\title{
Slovansko-staroirska vzporednica praslovansko *kry in staroirsko crú 'kri'
}

\author{
Luka Repanšek
}

Glede na stanje pri sigmatskem samostalniku srednjega spola *kreuH $\mathrm{H}_{2}$-es- v nekaterih glavnih historičnih indoevropskih jezikih (vedska stara indijščina, stara grščina) se na praindoevropsko stanje projicira proterokinetični akcentski model Jochema Schindlerja. Primerjava s prav tako podedovanim vzorcem, ki ga izkazujeta psl. *krŷ in stirs. crú, takšno domnevo potrjuje.

Ključne besede: slovanščina, keltščina, sigmatska debla, akcentskoprevojni vzorci, paradigmatska izravnava, laringalna teorija

\section{On the correspondence between Proto-Slavic *kry and Old Irish crú}

Based on evidence from some major historical Indo-European languages (Vedic and Ancient Greek), a proterokinetic accent pattern is usually reconstructed for the singular of the neuter $s$-stem noun $* k_{r e u H_{2}}$-es- (Schindler 1975). The pattern seen in Proto Slavic *krŷy 'blood' and its Old Irish cognate crú 'blood' is used as additional evidence to support this assumption.

Key words: Slavic, Celtic, $s$-stem nouns, ablaut paradigms, paradigmatic leveling, laryngeal theory

Ob pide. korenskem samostalniku' ${ }^{1} \mathrm{kreuH}_{2}-\mathrm{s}$ pomenom 'gosta kri; krvavo meso, surovo meso' (IEW: 621, NIL: 444ss.), ki se med drugim vsaj posredno ohranja v pridevnikih izsamostalniškega izvora tipa sti. krūrá-, av. xrūra-, oboje 'krvav, krut', $<* k r u H_{2}$-ró-, ${ }^{2}$ je na podlagi staroindijskega kraviṣs- (s) (ITed kravís, Red kravísas)

1 Za neprecenljiv strokovni komentar, ki je spremljal nastajanje tega prispevka, se iskreno zahvaljujem svoji mentorici, izr. prof. dr. Metki Furlan.

2 Čeprav je av. tvorba $x r \bar{u} r a$ - ob substantivnem $x r \bar{u}$ - 'kos krvavega mesa', če je slednje iz $* \mathrm{kruH}_{2}$ - in ne iz * $\mathrm{krouH}_{2}$ - (tako Meier-Brügger 2003: 290), lahko sekundarna, je ob odsotnosti ničtostopenjske (sklonske) oblike sigmatskega samostalnika $* * k r \bar{u}-s<* k r u H_{2}-s \mathrm{~V}$ stari indijščini ob sigmatskem kraviș- 'surovo meso' nujno predpostaviti tudi prisotnost korenskega samostalnika. Ob tem je morda sicer relevantna prav variantna rekonstrukcija av. $x r \bar{u}$ - $<* k_{r o u H}-$ (gl. zgoraj), ki bi lahko kazala na obstoj proterokinetičnega korenskega samostalnika. Slednje se sicer zdi neprepričljivo ob ohranjeni tožilniški obliki xrūm, če za xruuəm (IEW: 621, NIL: 445 ${ }^{4}$ ), ki kaže na ničtostopenjsko osnovo *kruH ${ }_{2}$ (imenovalnik in tožilnik praviloma med seboj nista v prevojnem razmerju). Vendar prim. germansko gradivo: stang. hrēaw (izglasni $w$ sekundarno ponovno vnesen iz rodilnika), stvn. (h)rō, stsaš. hrâo, hrā, kar je lahko po Holtzmannovem zakonu nastalo iz pgerm. * rauaz 'surov' (> zgerm. *hrauuaz, vendar stisl. hrár 'isto' z odsotnostjo okrepitve) 


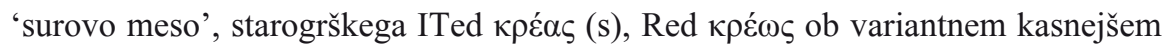

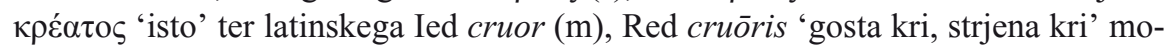
goče rekonstruirati sigmatski samostalnik srednjega spola s sorodnim pomenom. Ob dobro izpričanem proterokinetičnem vzorcu edninskih oblik samostalnikov srednjega spola ostalih soglasniških osnov se identičen vzorec predpostavlja tudi za sigmatske osnove (Schindler 1975: 263-264). Pide. baza s strukturo *CeC-es- se torej glede akcentskih procesov in s tem povezanega kvantitativnega prevoja obna-

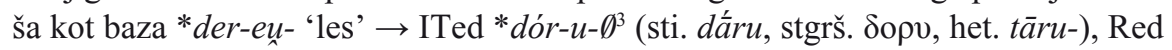
*dr-éu-s (sti. dróh), dalje primerjaj še * $H_{l} n e m-e n$ - 'ime' $\rightarrow$ ITed $H_{l} n o m-n g-\emptyset$, Red ${ }^{*} H_{1} n m-e ́ n-s^{4}$ ipd. Primerjava staroindijske paradigme s starogrško pokaže naslednji vzorec (po Schindlerju 1975: 265):
ITed sti. kravi-s
$=$ stgrš. $\kappa \rho \varepsilon ́ \alpha \varsigma$
$=\kappa \rho \varepsilon ́ \omega \varsigma$
$\kappa \rho \varepsilon \dot{\alpha} \alpha$
$<* \kappa \rho \varepsilon F \alpha-\varsigma$
$<* \mathrm{kreuH}_{2}-\mathrm{s}-\emptyset$
Red kraviș-as
Ded kraviș-e
$<{ }^{*} \kappa \rho \varepsilon F \alpha \sigma-\mathrm{o \zeta}$
$<* \kappa \rho \varepsilon F \alpha \varsigma-1^{5}$
$<*$ kreuH $\mathrm{H}_{2}$-és-os
$<*$ kreun $H_{2}-e ́ s-e i$

itn.

Treba je poudariti, da opisano stanje ni odraz neposredno podedovanega vzorca, saj se $\mathrm{v}$ posameznih sklonskih oblikah tako koren kot sklonilo pojavljata v polni stopnji. Pri tem je posplošitev polne stopnje korenskega dela lahko že zgodnja, polnostopenjsko rodilniško sklonilo pa se razlaga s sekundarnim vnosom sklonila

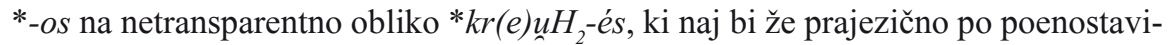
tvi izglasne geminate nastala iz *kreuHz-és-s (Schindler 1975: 263). Nadalje je za staroindijsko in starogrško stanje potrebno predpostaviti posplošitev sufiksa *-əs- >

in kaže na izsamostalniški pridevnik, nastal s tematizacijo korena $\mathrm{v}$ ojevski prevojni stopnji. V zvezi s tem se omenja tudi sti. kravyá- 'kri' = lit. kraũjas (cirkumflektirana intonacija zaradi odpada laringala v položaju pred $*_{i}$ po Pinaultovem zakonu), ki naj bi nastal s tematizacijo in nadaljnjo substantivizacijo iz oblike s Calandovim sufiksom ${ }^{*} \mathrm{krouH}_{2} i$ - (prim. av. xruui- kot prvi del kompozita), torej $*$ krouH $\mathrm{H}_{2}$-o-. Pri tem se ijevski element identificira tudi v baltoslov. pridevniku *kruui-no- 'krvav'> psl. *krbubnъ, lit. krùvinas (v tem primeru gre lahko za tip *oubnъ 'oven' $\mathrm{k}$ *oub (ca), identično lit. ãvinas $\mathrm{k}$ avis 'ovca' < * $H_{2}$ oui- (Brugmann 1906: 272)) (Nussbaum, GS Schindler, 1999; navedeno v Meier-Brügger 2003: 290).

3 Ojevska prevojna stopnja v imenovalniku je lahko ostanek prvotne akrostatične paradigme, ki je kasneje težila k proterokinetični (Schindler 1975: 264).

${ }^{4}$ Nastavitev proterokinetične paradigme pri leksemu za 'ime' se predpostavlja na osnovi slovanskega (*ib̆me $<*$ nomen, Red *ib̆mene), keltskega (ainm $<*$ *nmn, Red anmae $<$ *nmens) in staropruskega (emmens) gradiva (o tem že Cowgill 1965: 156). Vzglasni laringal je rekonstruiran na podlagi armenskega stanja, saj je v vzglasnem $a$ iz strukturnih razlogov možno videti le protetični $a$ laringalnega izvora (anun $<*$ anom). Po drugačni interpretaciji (v starejši in tudi še novejši literaturi) se na tem mestu nastavlja paradigma ITed ${ }^{*} H_{1} n e H_{3}-m n$, Red $* H_{10} n H_{3}$-mén-s (Schindler 1975: 263), ki je prav v luči zgoraj omenjenega gradiva problematična.

5 Pri konzonantih deblih je v stari grščini dajalniško sklonilo nadomestilo mestniško sklonilo - $<$ pide. *-i (Rix 1992: 120). 
sti. -iș-, stgrš. $-\alpha \sigma-($ Schindler 1975: 265), ki bi nastal na morfemskem šivu in se nato izluščil $\left(*_{-} \mathrm{H}_{2}-\mathrm{S}-\right)$, saj bi v nasprotnem primeru v stari indijščini pričakovali Red **kravasas $<*$ kreuH $\mathrm{H}_{2}$-ás-os.

Glede slednjega bi bilo treba reči, da bi bila za staroindijsko in starogrško paradigmo prav tako upravičena nastavitev amfikinetičnega vzorca, ki bi bil tipološko povsem primerljiv s stanjem v sti. Red námnas (k náman- 'ime') oz. het. lamnaš (k ITed lāman 'ime'). Tu je za pričakovani ničtostopenjski koren, polnostopenjski sufiks in ničtostopenjsko sklonilo (*CC-én-s) korenski del izpričan v polni stopnji (ta je bila, kot že omenjeno, lahko že v zgodnji fazi posplošena v celotni paradigmi), sufiksalni del pa v ničti. Do prehoda prvotnega proterokinetičnega vzorca $\mathrm{v}$ amfikinetični vzorec $\left(\mathrm{tj} .{ }^{*} C e ́ C\right.$-os, Red ${ }^{*} C C$-s-és) je sicer domnevno prišlo prav pod vplivom amfikinetičnih (oz. holokinetičnih) in histerokinetičnih akcentskoprevojnih paradigem (Schindler 1975: 263). Takšen amfikinetični sigmatski samostalnik se npr. ohranja v sti. uṣắs (ž) 'jutranja zarja'

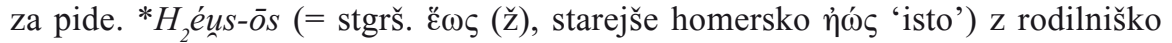
obliko $u s$-ás $<* u s-s-a s<* H_{2} u s-s$-és. Za staro indijščino in staro grščino bi torej lahko predpostavili tudi tale razvoj:

\begin{tabular}{|c|c|c|c|c|c|}
\hline Ted sti. & kraví-s & & $\kappa \rho \varepsilon ́ \alpha \varsigma$ & $<*_{\kappa} \rho \varepsilon F \alpha-\varsigma$ & $<* k r e u H_{2}-s-\emptyset$ \\
\hline ed & $k r a v$ & $=$ & $\kappa \rho \varepsilon ́ \omega \varsigma$ & $<{ }^{*} \kappa \rho \varepsilon F \alpha-\sigma-o \zeta$ & $<* \mathrm{kreuH}_{2}-\mathrm{s}-\mathrm{os}$ \\
\hline & kraví-s & $\approx$ & $\kappa \rho \varepsilon ́ \alpha$ & $<*_{\kappa} \rho \varepsilon F \alpha-\varsigma-1$ & $<* k$ \\
\hline
\end{tabular}

Takšnemu stanju pa lahko ustreza tudi lat. cruor (m) 'strjena, gosta kri' <*kreu $\mathrm{H}_{2}$ $\overline{o s}$, Red cruōris $\longleftarrow * *^{*}$ reuH $_{2}$-os-es ${ }^{6}$ (IEW: 621) s sekundarno spremembo v slovničnem spolu in popolnim priličenjem tipu honos -ōris 'čast', flōs -ōris 'cvet' itd. ${ }^{7}$

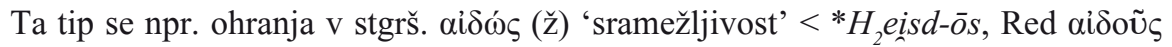
$<* \mathrm{H}_{2}$ eisd-os-os oz. v sti. pridevniku (su-)mánās (m/̌̌) 'dobro misleč' < *-men-ōs, Red (su-)mánasas <*-men-es-os (Rix 1992: 145).

$\mathrm{S}$ tem je povednost stare indijščine, stare grščine in latinščine za nastavitev prvotne proterokinetične akcentskoprevojne paradigme omajana, zato je v nadaljevanju dodano slovansko in keltsko gradivo, ki lahko takšen vzorec dodatno potrjuje. Na vzporednico psl. $k r \hat{y}=$ stirs. $c r u ́$, oboje s pomenom 'kri', v kateri se lahko ohranja sigmatski samostalnik, je bilo v literaturi že opozorjeno (Furlan 2008/2009), prav tako je bila rodilniška oblika obeh leksemov uporabljena za ponazoritev starejše proterokinetične akcentskoprevojne paradigme, pri čemer se je ničtostopenjski korenski del, izpričan v imenovalniku ednine, interpretiral kot posredni dokaz o nekdanji prisotnosti pričakovanega ničtostopenjskega korena $\mathrm{v}$ pide. rodilniku *kruH ${ }_{2}$-és-s (Furlan 2008/09).

6 V latinščini je sicer posplošena dolžina (izjema je arbor, -oris 'drevo') sufiksalnega dela sekundarnega nastanka, in sicer gre za analoški vnos iz imenovalnika.

7 Variantno je sicer latinski imenovalnik možno izpeljati tudi iz oblike $* k r u H_{2}-\bar{o} s$ z ničtostopenjskim korenskim delom (NIL: 444). 
S sinhronega stališča je psl. *krŷ, Red *kröue samostalnik ženskega spola $\bar{u}$-sklanjatve (stcsl. ITed $k r b v b,{ }^{8}$ Red $k r b v e$, Ded $k r b v i$ itn.), pri čemer so v stari cerkveni slovanščini izpričane tudi množinske oblike (Imn krъvi). ${ }^{9}{ }^{10}$ Do prehoda med samostalnike $\bar{u}$-sklanjatve je prišlo zaradi fonetičnega sovpada sklonskih oblik, s tem pa je moralo priti tudi do spremembe spola, saj gre za izvorni nevtrum (primerjaj sti. kravís,

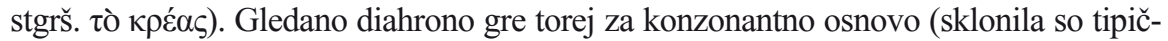
no atematska), toda brez neposrednih znakov o nekdanjem sigmatskem samostalniku. Kljub temu je zaradi primerjalnega gradiva upravičeno sklepati, da se v leksemu ohranja enaka sigmatska osnova. S tega stališča bi bilo v Ied psl. *kry $<* k r u H_{2}-s-\emptyset$ treba videti prav ničtostopenjski stranskosklonski koren ${ }^{*} \mathrm{kruH}_{2}$-, ki bi potrjeval proterokinetično akcentskoprevojno paradigmo tega pide. sigmatskega samostalnika (Furlan 2008/09). Slednja je bila v slovanščini posplošena na enak način, kakor je bila posplošena polna stopnja osnove v starogrškem ali staroindijskem leksemu. Sledila bi torej nastavitev

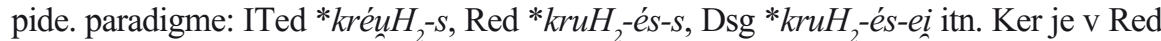

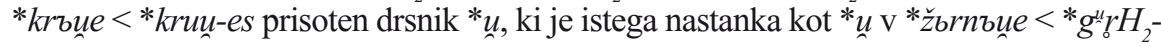
$n u-H$-es (Red k *žbrny 'mlinski kamen' $\left.<{ }^{*} g^{u} r H_{2}-n u-H\right)$, tj. kot polnilec zeva, ki nastane ob trku samoglasnika * $u$ z nekim drugim samoglasnikom po rednem odpadu laringala v medsamoglasniškem položaju, je treba predpostaviti, da je zaporedju $*_{-} u H_{2^{-}}$v Red sledil samoglasnik. Iz tega nadalje sledi, da psl. rodilniška oblika *krъune nedvomno kaže na izhodiščno *kruH $H_{2}$-és-s. Glede na dejstvo, da je odpad laringala v medsamoglasniški legi mlajši od obarvanja (pri $* H_{2}$ in $* H_{3}$ ) oz. neobarvanja (v primeru $* H_{1}$ ) morebitnega ejevskega samoglasnika ob njem, ${ }^{11}$ bi za psl. pričakovali rodilniško obliko **krbuo, ki je bila nedvomno že zgodaj nadomeščena s produktivnim rodilniškim sklonilom $*_{-e}<*_{-e s .}$ Prav tako bi Ded ${ }^{k} k r u H_{2}$-es-ei po rednem glasovnem razvoju dalo psl. **krbuosi, do česar najverjetneje nikdar ni prišlo, saj je morala biti kot nova osnova na sinhroni jezikovni ravni reinterpretirana stranskosklonska osnova, abstrahirana iz rodilniške oblike, torej *krъu-. S tem je bila odpravljena morebitna interparadigmatska alomorfija. Shematično:

Ied $* k r u H_{2}-s>$ psl. $* k r y$ (ohranjeno še v sln. $k r i ̂$, čak. $k r i,{ }^{12}$ slovin. $k r \tilde{a},{ }^{13}$ polab. kåråi, kråi, ${ }^{14}$ stpol. $\left.k r y^{15}\right)$

Red *kruH

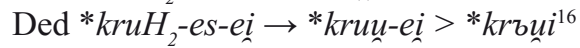

8 Stcsl. imenovalniška oblika je nastala s posplošitvijo tožilniške oblike; k procesu prim. sln. Ied kamen po Ted *kamenb za prvotni Ied *kamy.

9 Z RDOmn po $i$-sklanjatvi: Rmn krbvii <*-bib, Dmn krbvbmb, Omn krbvbmi.

${ }^{10}$ Stgrš. množinske oblike imajo izrazito kolektivni pomen: ITmn $\kappa \rho \varepsilon ́ \bar{\alpha}$ 'kosi mesa; mesne jedi' (Dokler 1915: 448) <*kreuH $H_{2}-s-H_{2}$, Rmn $\kappa \rho \varepsilon \tilde{\omega} v<* k r e u H_{2}-s-\bar{o} m$.

${ }^{11}$ Prim. npr. lat. iuvencus 'mlada krava' $<* H_{2} i u-H_{(3)} n_{0}-k^{\prime} O-$ in ne **iuvoncus, dalje stirs. fás 'prazen' $<* \mathrm{H}_{1}$ ueH $\mathrm{H}_{2}$-es-to-.

${ }^{12}$ Cres, Krk (Josip Lisac, Hrvatski dialekti i jezična povijest, Zagreb: Matica hrvatska, 1996, 46-47 (navedeno po Matasoviću 2008: 203)).

${ }^{13}$ Lorentz 1903: 259-260.

${ }^{14}$ Polański - Sehnert 1967: 76.

${ }^{15}$ Bezlaj 1982: 92.

${ }^{16}$ Ted **kruH $H_{2}-m>* k r b u s$ je le transponat, saj je bila tvorba možna šele po prehodu leksema v ženski spol. 
Identično stanje izkazuje tudi sorodno keltsko gradivo. Iz množice izpričanih staroirskih oblik crú, cráu, crao, chrúa, cro, cróu, cró, chrúi, crui, crai, ki jih navaja eDIL, je Joseph (1988) izluščil dve semantično in strukturno različni paradigmi. ${ }^{17}$ Relevantne oblike, ki tvorijo paradigmo staroirskega leksema za 'kri', so: I crú, R cráu, cráo, cróu, cró, D crú, T (?) crú (Joseph 1988: 181, GOI § 310). Spol je vprašljiv (tako tudi GOI $\S 310$ ), pri čemer znakov o obstoju množinskih oblik ni, prav tako je vpadljiva formalna prekrivnost imenovalniške in tožilniške oblike, kar lahko priča o tem, da gre za samostalnik srednjega spola. Takšno stanje bi bilo glede na primerjalno gradivo tudi pričakovano. Imenovalniška oblika kaže na izhodiščno $* k r \bar{u} s<* k r u H_{2}-s(=$ psl. $* k r y)$. Variantne rodilniške oblike so izpeljive iz prvotnega **crou [krou] z diftongom *ou, ki se je v naglašenem položaju v izglasju podaljšal (McCone 1996: 138) ${ }^{18}$ in nato sovpadel z diftongom *āu <áu, áo> (GOI $\S 72),{ }^{19} \mathrm{v}$ nadaljnjem razvoju pa se je monoftongiziral $\mathrm{v} * \bar{o} \cdot{ }^{20}$ Izhodiščni rodilnik ednine $* k r u H_{2}$-és-s bi še predprakeltsko preko *kru-u-as dal pkelt./pgoid. *krouas s prehodom zaporedja $*_{-u u-~} *_{-o u-}{ }^{21}$ pri čemer je bilo rodilniško sklonilo lahko zamenjano s produktivnim *-os (po glasovnem razvoju sicer nedokazljivo). Dajalniška oblika crú prav tako kakor psl. *krъui iz predpostavljenega izhodiščnega pide. *kruH $H_{2}$-es-ei ni nastala po fonetični poti, saj bi v slednjem primeru najverjetneje pričakovali stirs. ${ }^{*}$ croí, kar ni izpričano. Treba je predpostaviti, da se je, podobno kot v slovanščini, soobstoj oblik *kruuos/as : *kruuesei $/ i$ odpravil v prid transparentnejši tvorbi *kruu- + sklonilo, od koder se je tvorila dajalniška oblika *kruu-i ${ }^{22}$ $>$ zgirs. ${ }^{*} k r u u$ > stirs. crú [krū]. Izpričana oblika to dodatno dokazuje, saj je morala biti naplastitev dajalniškega sklonila na novonastalo osnovo že zgodnja, tj. prakeltske starosti, ker je ovirala prehod zaporedja *-uu- $*_{-o u-}{ }^{23}$ Če je tožilniška oblika crú z imenovalniško crú formalno resnično prekrivna le na stopnji stare irščine (tj. zaradi fonetičnega sovpada oblik), je, kot je bilo že omenjeno zgoraj, vprašljivo, saj bi pričakovali, da je leksem obdržal izvorni srednji spol in je s tem formalna identičnost obeh sklonskih oblik podedovana. Po fonetični poti se oblika sicer da izvajati iz mlajšega tožilnika *kruu-m (rekonstrukcija, ki bi segala v predprakelt-

${ }^{17}$ Oblike cró, cruí, crú, cró, cráo, crai tvorijo tematski samostalnik moškega spola s pomenoma 'krvna odkupnina' ter 'nasilna smrt': Ied cró < cráu < zgirs. *krouah < *kruHzos, Red cruí, croí $<* k r u u \bar{\imath}<* k r u H_{2}-\bar{\imath}$, Ded crú $<* k r o u \bar{u}<* k r u H_{2}-\bar{o} i$, Ted cráo, cró $<$ *krouan $<* \mathrm{kruH}_{2}$-om, Imn cruí, crái $<*$ kroūi $<* k_{\text {rum }}-\bar{\imath}$ (Joseph 1988: 182).

${ }_{18}$ Prim. bóu (Red k bó 'govedo') < *bou <* * $g^{u}$ ou-os.

${ }^{19} \mathrm{~V}$ času stare irščine (8.-9. stoletje) je diftong *āu ujet ravno sredi razvoja proti monofton$\mathrm{gu} * \bar{o}<0$ ó , pri čemer je vmesna faza $\mathrm{v}$ zapisu občasno izražena z digrafom áo (GOI § 69).

${ }^{20}$ Prim. variantno bó ob bóu (Red k bó 'govedo') < *bou < * $g^{u}$ ou-os.

${ }^{21}$ Prehod je že prakeltske starosti (McCone 1996: 55), prim. stirs. oitiu 'mladost' [oidd'u] < zgirs. *ouædūh < pkelt. *iouantūt- $\left.<* H_{2} i u-H_{(3)}\right)^{n-t u H t-(=~ l a t . ~ i u v e n t u ̄ s ~ ' m l a d i n a ') . ~}$

${ }_{22}$ Gre za prakeltsko dajalniško sklonilo (po izvoru najverjetneje lokativni $*_{-i}$ ), produktivno pri konzonantnih deblih. Glede na pričakovani razvoj *kruui > arhirs. *kruu'> stirs. **croí je potrebno predpostaviti, da je tak * $i$ odpadel že pred apokopo zadnjih zlogov v irščini, tj. pred obdobjem zgodnje irščine (Joseph 1988: 181-182; Uhlich 1995: 28).

${ }^{23} \mathrm{H}$ glasovnemu zakonu uu $>$ ou /__ [-i] prim. pkelt. *druuid- $>$ zgirs. *druuih $>$ arhirs. *druu'> stirs. druí (Uhlich 1995: 16; McCone 1996: 55). 
ski čas, torej $* * k r u H_{2}-m$, pace Joseph (1988: 181) ni upravičena), od koder je po Stangovem zakonu $* k r u m m>* k r u \bar{m}>* k r u \bar{u} n^{24}>$ stirs. crú, vendar takšno izpeljavo otežuje dejstvo, da naj bi bila sklonila v času nastanka nove osnove *kruu- že izoblikovana (pide. ${ }^{*}$-m $>$ pkelt. ${ }^{*}$-am) in bi torej pričakovali $*$ kruu-am $>* k^{k r o u e m}{ }^{25}>$ stirs. **croí.

V stari irščini ${ }^{26}$ in slovanščini je bila torej prvotna proterokinetična paradi-

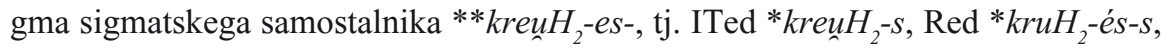
preoblikovana na povsem vzporeden način. Obenem pa prav jezikovno dejstvo, ki je sprožilo potrebo po preoblikovanju (vključno s povednimi rodilniškimi oblikami), ponuja vpogled v zgodovino akcentskoprevojnih procesov, v katere so bila vključena sigmatska debla srednjega spola.

\section{Krajšave}

arhirs. $=$ arhaičnoirsko; arm. $=$ armensko; av. $=$ avestijsko; čak. $=$ čakavsko; gal. $=$ galsko; het. = hetitsko; keltib. = keltibersko; korn. = kornijsko; lat. = latinsko; lit. $=$ litavsko; $\mathrm{m}=$ samostalnik moškega slovničnega spola; pgerm. = pragermansko; pgoid. $=$ pragoidelskokeltsko; pide.$=$ praindoevropsko; pkelt. $=$ prakeltsko; polab. $=$ polabsko; psl. $=$ praslovansko; $\mathrm{s}=$ samostalnik srednjega slovničnega spola; $\operatorname{sln} .=$ slovensko; slovin. $=$ slovinsko; srkimr. $=$ srednjekimrijsko; stang. $=$ staroangleško; stcsl. $=$ starocerkvenoslovansko; stgrš. $=$ starogrško; sti. $=$ staroindijsko; stirs. $=$ staroirsko; stisl. $=$ staroislandsko; stpol. $=$ staropolsko; stsaš. $=$ starosaško; stvn. $=$ starovisokonemško; zgerm. $=$ zahodnogermansko; zgirs. = zgodnjeirsko; $\breve{z}=$ samostalnik ženskega slovničnega spola

\section{Viri in literatura}

Bezlaj 1982 = France Bezlaj, Etimološki slovar slovenskega jezika II, Ljubljana: Mladinska knjiga, 1982.

Brugmann 1906 = Karl Brugmann, Grundriss der vergleichenden Grammatik der indogermanischen Sprachen II/1, 1906 (ponatis 1967).

Cowgill 1965 = Warren Cowgill, Evidence in Greek, v: Evidence for Laryngeals, ur. Werner Winter, The Hague: Mouton, 1965 (Janua Linguarum, Series Maior II), 142-180.

${ }^{24}$ Izglasni *-m je že zgodaj prešel v *-n (GOI $\left.§ 176\right)$. Prakeltska starost je ob gal. Ted ž $\delta \varepsilon \kappa \alpha \nu \tau \varepsilon v<*$ dekmtām (McCone 1996: 57) in keltib. Ted ž (?) aratim 'oranje; orna zemlja' (NIL: $164-165)<* H_{2} e r H_{3}-t i-m$ sicer vprašljiva.

${ }^{25} \mathrm{O}$ prehodu zlogotvornega $* m \mathrm{v}-e m>-e n \mathrm{v}$ izglasju priča vselej palatalizirana fonetična vrednost izglasnega konzonanta $\mathrm{v}$ tožilniku ednine konzonantnih debel, prim. stirs. carait [karad'] (Ted h carae 'prijatelj') < zgirs. *karēdæn $<* k H_{2} r$-ánt-mo.

${ }^{26}$ Britanska keltščina kaže na (podedovano?) tematizirano obliko $* k r u H_{2}-o / \bar{a}>$ srkimr. creu, korn. crow, oboje 'kri'. 
Dokler 1915 = Anton Dokler, Grško-slovenski slovar, Ljubljana, 1915 (ponatis 1999).

eDIL = Electronic Dictionary of the Irish Language [http://www.dil.ie].

Fraenkel 1962 = Ernst Fraenkel, Litauisches etymologisches Wörterbuch, Heidelberg: Carl Winter, 1962.

Furlan 2008/09 = Metka Furlan, Členitev (pra)indoevropščine, izroček k predavanju pri predmetu Hetitščina II, študijsko leto 2008/09.

GOI = Rudolf Thurneysen, A Grammar of Old Irish, Dublin: Dublin Institute for Advanced Studies, 1946 (ponatis 1993).

IEW = Julius Pokorny, Indogermanisches etymologisches Wörterbuch, Bern, München: Francke Verlag, 1949-1959.

Joseph 1988 = Lionel Joseph, The inflexion of OIr. crú, Ériu 39 (1988), 169-187.

Lorentz 1903 = Friedrich Lorentz, Slovinzische Grammatik, Sankt Petersburg, 1903, 259-260.

Matasović 2008 = Ranko Matasović, Poredbenopovijesna gramatika hrvatskog jezika, Zagreb: Matica hrvatska, 2008.

Matasović 2009 = Ranko Matasović, Etymological Dictionary of Proto-Celtic, Leiden - Boston: Brill, 2009.

McCone 1991 = Kim McCone, The inflection of OIr. bó 'cow' and the etymology of buchet, Eire 42 (1991), 37-44.

McCone 1996 = Kim McCone, Towards a relative chronology of ancient and medieval Celtic sound change, Maynooth: The Cardinal Press, 1996.

Meier-Brügger 2003 = Michael Meier-Brügger, Indo-European Linguistics, Berlin - New York: Walter de Gruyter, 2003.

NIL = Dagmar Wodtko idr., Nomina in indogermanischen Lexicon, Heidelberg: Winter, 2008.

Polański - Sehnert 1967 = Kazimierz Polański - James Allan Sehnert, PolabianEnglish Dictionary, The Hague: Mouton \& Co., 1967.

Rix 1992 = Helmut Rix, Historische Grammatik des Griechischen, Darmstadt: Wissenschaftliche Buchgesellschaft, 1992.

Schindler 1975 = Jochem Schindler, Zum Ablaut der neutralen s-Stämme des Indogermanischen, v: Flexion und Wortbildung: Akten der V. Fachtagung der Indogermanischen Gesellschaft, Regensburg, 9.-14. September 1975, ur. Helmut Rix, Wiesbaden: Dr. Ludwig Reichert Verlag, 1975, 259-267.

Uhlich 1995 = Jürgen Uhlich, On the fate of intervocalic *-u- in Old Irish, especially between neutral vowels, Eire 46 (1995), 11-48.

Walde 1965 = Alois Walde, Lateinisches etymologisches Wörterbuch, Heidelberg: Carl Winter, 1965. 


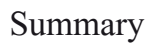

Based on evidence from Vedic NAsg kravis 'raw meat', Gsg kraviș-as = Ancient

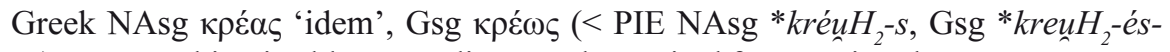
$o s$ ), a proterokinetic ablaut paradigm can be posited for PIE singular neuter $s$-stems. However, in light of amphikinetic non-neuter s-stems of the type Ved. ușấs (fem.) 'dawn', Gsg uṣás (<* ${ }_{2} \mathrm{H}_{2} e ́ u s-\bar{o} s$, Gsg $\left.{ }^{*} \mathrm{H}_{2} u s-s-e ́ s\right)$, the reconstruction of these forms is reviewed and a possible amphikinetic pattern (of analogical origin) is recognized, in which case the evidence from Slavic and Celtic becomes crucial for the preservation of the reconstructed proterokinetic ablaut pattern.

The Proto-Slavic and Old Irish nominative singulars PSl. *kry 'blood' = OI crú 'blood' $<{ }^{*} \mathrm{kruH}_{2}-\mathrm{s}$ secure the expected zero-grade in the oblique cases lacking in both Vedic and Old Greek by exhibiting the generalized zero-grade throughout their respective paradigms. In addition, the genitive forms PSl. Gsg *krb̈ue = OI cráu (easily derived from Proto-Celtic *kru-u-as/os < PIE *kruH $H_{2}-e ́ s-s$ ) demand a full-grade suffixal element and hence conform to the reconstructed proterokinetic ablaut pattern.

Both the Slavic and Celtic genitive forms must have undergone additional reshaping by eliminating the allomorphy that arose due to the coloring of the suffix *-e- that preceded laryngeal loss in an intervocalic environment, whereupon a new base *kruu- was extracted from the reshaped genitives, which in turn provided the starting point for the formation of other cases (PSl. Dsg *krbui, OI crú, etc.). 